\title{
Genre Analysis: Studying Authorial Stance in the Pakistani Research Articles of Business and Management Sciences
}

\author{
Arjamand Bilal ${ }^{1} \&$ Wasima Shehzad ${ }^{2}$ \\ ${ }^{1}$ Department of Social Sciences and Humanities, National University of Computers and Emerging Sciences \\ (FAST-NUCES), Islamabad Campus, Islamabad, Pakistan \\ ${ }^{2}$ Faculty of Social Sciences and Humanities, Air University, Islamabad, Pakistan \\ Correspondence: Arjamand Bilal, Department of Social Sciences and Humanities, National University of \\ Computers and Emerging Sciences (FAST-NUCES), Islamabad Campus, Islamabad, Pakistan. E-mail: \\ arjumandbilalhussain@gmail.com
}

Received: November 10, 2018 Accepted: December 14, 2018 Online Published: January 7, 2019

doi:10.5539/ijel.v9n1p455 URL: https://doi.org/10.5539/ijel.v9n1p455

\begin{abstract}
The notion of authorial stance has received much attention internationally in recent years which has increased its complexity in terms of its relationship with genre-pedagogy and genre-awareness. Metadiscourse markers are used by academic writers in order to build and maintain relationship with their readers. This is done by use of appropriate language either to influence them or show a certain degree of agreement or disagreement. The present study investigated the stance features as they appeared in the genre of research article introduction section written by seasoned authors. 50 papers from the field of Business and Management Sciences were studied in order to explore the language features projecting authorial stance or author's voice used by authors. Hyland's (2005b) Model of Academic Interaction was used to study the authorial stance. The findings showed that the authors used a considerable degree of stance features in their research articles. The study may provide some useful insights regarding teaching the writing of research article, understanding the concepts of genre-competence and genre-production.
\end{abstract}

Keywords: genre, genre analysis, genre pedagogy, genre-based instruction, research article writing, stance, authorial stance

\section{Introduction}

Educational-instructional system in Pakistan has been a neglected area of research and discussion since independence. If I turn back the pages of history, I will not be wrong to say that the educational pedagogy and instruction has been a phenomenon of not-so-important a concern for the authorities taking care of this extremely crucial foundation of our nation. This can be rightly said because the main focus of the Federal Ministry of Education and, hence, the provincial governments has been curriculum planning, curriculum design, accreditations from one after another nationally and internationally standardised systems, as well as financing of scientific research and development for hardcore sciences in a maximum number of cases. The point here is not to criticise the efforts the ministry and the federal governments have been making, but to highlight the fact that funding for research and development of teacher training and educational pedagogy is limited to mostly paper-work and formal records. Practical implementation of such theoretical ideas is not least found anywhere in the disciplines of humanities and social sciences.

Pakistani educational system is divided into six main categories with preschool being the first step and university degree programs being the final. Universities offering undergraduate and graduate programs prioritise and/or minimise their main goal to make students have an in-depth knowledge of core courses, i.e. the absence of teaching genre-awareness in the light of genre-production reflects a setback. Before I elaborate more on this issue, I would like to explain the term 'genre'. Genre is a term for grouping texts together. These texts are grouped together on basis of their similar features. For example, the genre of research article, abstract, research proposal and email are a few to name (Hyland, 2006). These genres are grouped together on basis of similarity of their structure, organization, pattern and language. Members of a genre family are said to have family resemblance which sheds light on the idea how cousins and siblings share same features as of everyone else in the family (Wittgenstein, 1980; 1958). An emerging field of study is genre analysis which studies the schematic 
structures and linguistic patterns used by authors/producers of these genres. Knowing about these delicacies of language and pattern is called genre-awareness. If genre pedagogy is left neglected, I am afraid our educational systems will take a lot more years to meet the international systems of quality education, all this is being said through the lens of genre-research in the field of BMS.

When I say genre-pedagogy, I mean the techniques our teachers need to practice inside the classrooms to empower our students on writing or producing different forms of genres. At the university level, our students study core courses and work diligently on scoring the best possible grades and securing the most worthy a CGPA, but the problem arises when they want to study abroad after graduating from these universities. Any prestigious institution outside Pakistan requires a research article publication as a prerequisite. Our students are highly prone to failure there because they are not trained to write a research article for their said field of study. Their attempts, one after another, lead to failure and, hence, frustration, when their research articles, research proposals and other such documents of extreme importance and consequential nature fail to meet the international standards. None of the universities in Pakistan offers a course during the span of their four-year degree plan where they are taught a course titled 'Research Article Writing'. Learning to write a research article remaining within the boundaries of any discipline is a major skill which our university graduates lag behind in. The genre of the research article is the need of the day, not that I mean that other genres are less important. Studying and understanding a genre is called unpacking the black-box of academic discourse (Swales, 1990). Because academic discourse or academic language has to be very specific, precise, and focused, Hyland and Swales both emphasise on its technique-based instruction (Swales, 1984; Hyland, 2000).

Technique-based teaching of genre involves all important notions required by the target community. For example, if someone studies engineering, they should know the style of language and structures used in the discipline of engineering by the engineer's discourse community. A discourse community is a group of people from the same discipline who use the same type of standardised language which is required and, hence, accepted by their discipline. Likewise, someone striving to excel in the field of medicine needs to know the genre and genre conventions of the discourse community of medical experts. This includes knowing to write a research article, a research proposal, and/or other important documents which are needed to be a part of a particular field. Having genre-awareness means knowing the elements of intertextuality and interdiscursivity, latter being text-externals while former being text-internals. Intertextuality lets a researcher study the organisational patterns of text while interdiscursivity explores the language which authors use internally inside a text to maintain the standard and boundaries of the discipline. Both of these approaches are used to study a text through the analytical lens. However, this article addresses the genre of RA via the interdiscursive lens. 50 RAs from the field of BMS were studied for stance features as proposed by Hyland's (2005b) in his Model of Academic Interaction (see Figure 1 in the Data Analysis). The model explores the type of language which authors from the field of BMS prefer to use in order to build their authorial stance and reader engagement. Stance, also called 'author's voice' is the term which advocates how authors of a particular genre take a position to communicate certain messages to their readers (Hyland, 2001). The markers of Engagement determine the presence of potential readers within the text (Hyland, 2002a). It focuses on treating a genre's readers as participants. This article has explored stance features only. Genre-awareness, in term of RA writing, empowers authors to produce genre(s) in a more systematic manner (Allami \& Serajfard, 2012).

The higher education system of Pakistan and Pakistani universities need to adopt the approach offered by genre analysts. Although an emerging field of study it is, the scope it stretches and the opportunities it offers to the educational-instructional-pedagogy is immaculate.

\subsection{Background of the Study}

The discipline of business and management sciences has a lot of scope nationally and internationally. It is important to look at how the discipline achieved the status it has today. In this regard, I would like my readers to have a look at where the discipline started to gain fame and value from. It was the work of Chandler (1962) which brought worldwide fame to the field. His career spanned over more than six decades during which he worked on influential monographs and had multiple research publications. His works are considered to be the powerhouse for organizational sociologists and business management researchers (Bellah, 1967). He is believed to be the guru of business and management studies (Fligstein, 2008). In the recent past, Friedman, Bowden and Jones (2003) at Harvard worked collaboratively to develop some useful and practical research and teaching techniques in Asian, American and Latin-American cultures.

In an international context, Barbero's (2008) work in Latin America was given much importance by the international community. He studied the development of business and the discipline of business studies from the 
1960s to 2007. According to him, it was not until the 1980s that the Latin-American business got rid of the title of being under-developed and disoriented. Toms, Wilson and Wright (2015) state that business history in England started in 1958 after the journal publication by the University of Liverpool. It was only after that when latest management strategies and themes started to incorporate their ideas with the English business, networks, corporate governance, human resource management and marketing.

In a national context, the scope of business and management is vast. Pakistan is the country with a rich history but with a lot of ups and downs as it was given only 34 out of 921 working industrial units at the time of partition in 1947. It has gone through multiple phases during the establishment of its business and industry. However, after that, its educational sector has flourished a lot as it offers students of business and management sciences some options to choose from including marketing, finance, banking, human resource and consultation. With Institute of Business Administration (IBA), Karachi, being the first one of its own kind of establishment in Pakistan in 1955, Pakistan has some very prestigious institutes of business and management including Lahore University of Management Sciences (LUMS), Lahore, Shaheed Zulfiqar Ali Bhutto Institute of Sciences and Technology (SZABIST), Karachi, Sukkur Institute of Business Administration, Sukkar, and Institute of Management Sciences, Peshawar. All these and many other institutes produce a large number of graduates every year, but one thing is common about many of these graduates. They have not received formal education or instruction on the writing of research article in the light of their discourse community. In other words, they are not genre-competent regarding research article production.

The main purpose of writing this article is to educate, and aware our discourse community of English language teachers about the importance this very genre of research article writing holds. Keeping that in mind and elaborating more on the importance of genre-based instruction and its competence, the coming sections shed light on some of the recent studies conducted worldwide.

\subsubsection{Function of Interaction}

Navidi and Ghafoori (2015) explored the features of stance and engagement by comparatively studying the two part-genres (when a part of a genre is explored), i.e. introduction and discussion sections of research articles from the field of applied linguistics at an Iranian university. Through the study of a sample of 60 articles, they came up with like conclusions as by the studies from several researchers in the recent past, i.e. the stance and engagement markers or features should be highlighted and emphasized upon for the production of any research article. In Pakistani context, it is the need of the day to understand the importance of these features which if inculcated and incorporated in our genre-based pedagogy, can bring marvelous changes towards the better future of our young graduates. The researchers also concluded that appropriate knowledge of accurate use of stance and engagement features would help authors/writers produce generically, strategically, and linguistically more influential research articles.

\subsubsection{Studying Metadiscourse}

Another similar study by Sayah and Hashemi (2014) in the fields of sociology, linguistics, and education investigated 90 research articles to find out that the features suggested by Hyland in his model were present but with much variation in these disciplines. The presence of persuasive stance was much obvious, but self-mention was not found in articles by Persian writers. Strategies like the use of passive voice and careful style of expression of opinion were used as well. In the research articles from the field of sociology, self-mentioning pronouns were used as the most efficient tool of marketing. In order to reduce the presence of vagueness, modal verbs were used. None of the authors used the modal verb 'may'. In the research articles from authors in the field of linguistics, different conclusions were drawn. Verb 'appear' was used quite a lot of times depicting the passiveness of the author. Educational research articles used the verb 'think' for the like reasons. Sayah and Hashemi (2014) came up with conclusions of emphasizing the importance of teaching varying language structures and patterns in particular disciplines so that authors from each discipline know about the do's and do not's of their specific fields when it comes to research article writing. Connecting this research with the Pakistani setting, the message is very evident, i.e. the need of formal genre-based instruction at universities.

\subsubsection{Metadiscourse across Disciplines}

Akbarpour and Sadeghoghli (2015) carefully examined 70 research articles from 7 diverse fields of study. They eventually claimed that the distribution of stance and engagement markers appeared with a hierarchy of language use among and across disciplines. Strategies like the use of self-mention, hedges and boosters were emphasized the most, but variations across and among disciplines were observed. To say it in a nutshell, it is of crucial importance that Pakistani universities start to train first their teachers and then their students about the importance of genre-awareness and, hence, genre-production via the use of genre-based pedagogy. 


\subsection{Objective of the Study}

The present study intends:

- To explore the features of Hyland's Model of Academic Interaction (2005b) which are present in the part-genre (introduction sections) of RAs of BMS community.

- To understand the significance of the authorial stance features, as proposed by the authors.

\subsection{Research Question}

The study has the following questions:

- What features of stance, as proposed by Hyland (2005b), are present in the RAs from the field of BMS?

- What is their potential significance?

\section{Methods}

This study presents the analysis of the part-genre, i.e. Research Articles of Business and Management Sciences in Pakistan, in order to explore the stance features in the light of metadiscourse as used in the field of Business and Management Sciences. Fifty research papers were analysed using Hyland's MAI (2005b). The model descend from the field of ESP and studies genre, its conventions, patterns, metadiscoursal features through the lens of interdiscursivity, hence, providing more valid findings for those who intend to study the genre of RA and explore its rhetorical conventions in great details.

\subsection{Data Collection and Sampling}

The present study has been conducted on a sample of 50 RAs from the fields of Business and Management Sciences. The samples were collected from 5 HEC-approved, (Y-Category) journals (JBE, BR, PBR, GMACS, NICE) from the discipline of Business and Management Sciences from the years 2015 and 2016. For each one of the journals, two issues containing 5 papers each were chosen.

\subsection{Types of Analyses}

It is the methodology of any research work that validates its authenticity and reliability. The present study used both the quantitative and qualitative methods of analysis. Both quantitative and qualitative methods help in making the readers understand not only the frequency in use of any strategy, the regularity of occurrences of linguistic and rhetorical features but also the effects of all these characteristics on the production and quality of BMS RAs when studied through Hyland's MAI (2005b).

\section{Data Analysis}

The model of interaction as proposed by Hyland has two main branches, the first one being the stance. Stance, in simple words, is the author's point of view. There is a certain way authors use language in research articles in order to meet certain standards and norms of the discourse community they belong to. These authors use language to acknowledge, construct and negotiate social relations (Hyland, 2006).

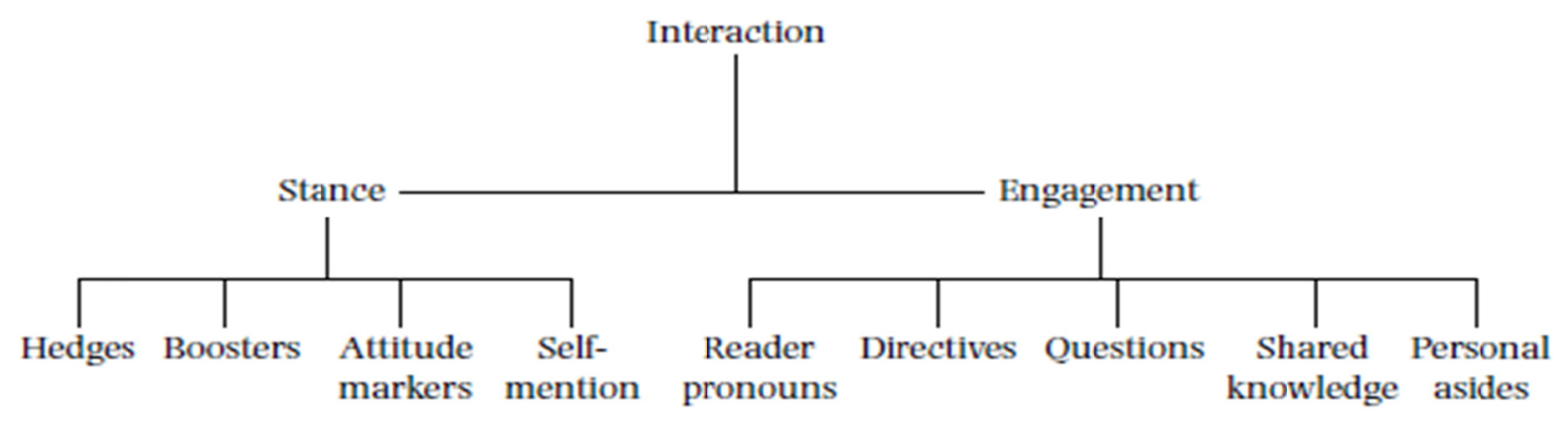

Figure 1. Ken Hyland's Model of Academic Interaction

Fifty introduction sections of research articles from the field of business and management sciences were studied for the present research. Detailed discussion on each one of the features of stance is as follows: 


\section{1) Hedges}

These are words which express an author's decision when they decide to hold back opinions and statements of certainty and commitment. This is careful use of words so that their statements are taken more like the presentation of the information and less of an opinion. Out of 50 RAs studied for this article, 36 had a significant usage of hedges which made the occurrence of hedges to be $72 \%$. The careful study showed that among the words indicating hedges and their usage, the one which was most frequently found was "May" in 28 articles. "Can" secured the position of being the second highest most frequently used indicator of hedges found in 25 articles from the discipline of business and management sciences. Other indicators of hedges included could be, can be, might, could, might be, ought to and can be. Table 1, below, shows the representation of the same data in detail.

Table 1. Types of hedges and their occurrences in 36/50 BMS RAs

\begin{tabular}{llll}
\hline Types of Hedges & Introduction Number & Total Occurrences & Percentage (out of 36 BMS RAs) \\
\hline Could be & INTRO.1 & 1 & $2.7 \%$ \\
May & INTRO.1, INTRO.8, INTRO.14, INTRO.16, INTRO.20, & 28 & $77.7 \%$ \\
& INTRO.25, INTRO.29, INTRO.32, INTRO.35, INTRO.36, & & \\
& INTRO.37, INTRO.39, INTRO.42, INTRO.44, INTRO.46, & & \\
& INTRO.48 & & $19.4 \%$ \\
Can be & INTRO.4, INTRO.17, INTRO.41, INTRO.47, INTRO.48 & 7 & $5.5 \%$ \\
Might & INTRO.22, INTRO.24 & 2 & $13.8 \%$ \\
Could & INTRO.23, INTRO.24, INTRO.27 & 5 & $2.7 \%$ \\
Might be & INTRO.28 & 1 & $2.7 \%$ \\
Ought to & INTRO.33 & 1 & $69.4 \%$ \\
Can & INTRO.2, INTRO.4, INTRO.6, INTRO.7, INTRO.14, & 25 & \\
& INTRO.17, INTRO.19, INTRO.21, INTRO.24, INTRO.31, & & \\
& INTRO.32, INTRO.33, INTRO.34, INTRO.35, INTRO.39, & & \\
Can be & INTRO.44, INTRO.47, INTRO.48, INTRO.49 & 6 & $16.6 \%$ \\
\hline
\end{tabular}

Hence, it is safe to say that teaching of genre-based RA writing requires a good understanding of the possible use of hedges as the findings suggest.

\section{2) Boosters}

Boosters are words which refer to the strong confidence about a statement or fact shown by the author. It shows the quality of conviction as well as a commitment which leads to having readers' confidence because these words project a lot of assurance and force. Using boosters leaves no room for uncertainty or vagueness about any facts or statements showing information (Hyland, 1999). Words like definitely, surely, certainly are projectors of boosters. Such words were found in 35 out of 50 research articles from the discipline of business and management sciences which made a total of $70 \%$ occurrence. It was also concluded that sometimes words like have to, must and should be used to show imperatives which gave an impression of boosters. Main expressions of boosters used by these authors were really, should have, explicitly, significantly, extremely, particularly, ultimately, especially, necessarily, highly, truly, extensively, strongly, majorly, specifically, fundamentally, obviously, completely, clearly, seriously, actually and primarily. Use of boosters by $70 \%$ of these authors elucidates the importance of stress and surety about the topic under discussion. The boosters used by the authors from the BMS community can be seen in Table 2 . 
Table 2. Types of boosters and their occurrences in BMS RA

\begin{tabular}{|c|c|}
\hline Introduction Number & Types of Boosters Occurred \\
\hline INTRO.1 & Really, must be, should have, explicitly, should not \\
\hline INTRO.2 & Significantly, particularly, extremely, must, ultimately \\
\hline INTRO.3 & Have to \\
\hline INTRO.4 & Particularly \\
\hline INTRO.5 & Particularly, especially, necessarily \\
\hline INTRO.6 & Implicitly, should \\
\hline INTRO.7 & Must \\
\hline INTRO.8 & Highly, significantly \\
\hline INTRO.9 & Particularly, especially, truly, extensively \\
\hline INTRO.10 & Strongly \\
\hline INTRO.11 & Must, highly \\
\hline INTRO. 12 & Majorly \\
\hline INTRO.13 & - \\
\hline INTRO. 14 & - \\
\hline INTRO. 15 & Particularly, must, ultimately \\
\hline INTRO.16 & Specifically \\
\hline INTRO. 17 & Should, fundamentally, significantly \\
\hline INTRO.18 & - \\
\hline INTRO.19 & Should \\
\hline INTRO.20 & - \\
\hline INTRO.21 & - \\
\hline INTRO.22 & Definitely, ultimately \\
\hline INTRO.23 & - \\
\hline INTRO.24 & - \\
\hline INTRO. 25 & - \\
\hline INTRO.26 & Especially \\
\hline INTRO.27 & Obviously \\
\hline INTRO.28 & - \\
\hline INTRO.29 & Ultimately \\
\hline INTRO.30 & Undoubtedly \\
\hline INTRO.31 & No doubt, especially \\
\hline INTRO.32 & Should, must, ultimately, strongly \\
\hline INTRO.33 & Certainly, surely \\
\hline INTRO.34 & Mostly \\
\hline INTRO.35 & - \\
\hline INTRO.36 & Mainly, completely \\
\hline INTRO.37 & Mostly \\
\hline INTRO.38 & - \\
\hline INTRO.39 & Ultimately, highly, clearly, seriously, should \\
\hline INTRO.40 & - \\
\hline INTRO.41 & Certainly, should \\
\hline INTRO.42 & Specifically, especially \\
\hline INTRO.43 & - \\
\hline INTRO.44 & - \\
\hline INTRO.45 & Significantly, especially \\
\hline INTRO.46 & - \\
\hline INTRO.47 & Ultimately, should \\
\hline INTRO.48 & Actually \\
\hline INTRO.49 & Should \\
\hline INTRO.50 & Primarily, extensively \\
\hline Percentage & $70 \%$ \\
\hline $35 / 50$ & \\
\hline
\end{tabular}

As Table 2 suggests quite an extensive use of boosters by the BMS community, it is evident to take a note of this very important language convention in the light of its possible use. Smart use of boosters can convey self-assurance and convince readers about the author's knowledge and command on the subject under discussion. 


\section{3) Attitude Markers}

These words which classify as terms and certain grammatical categories show the emotions and feelings of the author about the topic. Attitude markers play an important role in creating reader-agreement. These expressions show sentiments and emotions in a way that readers get more seriously involved with the author's ideas. A great variety of attitude markers used by business and management research article writers consisted of a mix of adverbs and adjectives inculcating the feeling of association and connection with other researchers or ideas presented by the same research by the author themselves. As the name suggests, attitude markers illustrate the attitude of the authors from a field of study, in this case, it was authors from the field of business and management sciences. The term attitude is synonymous to showing emotion towards a particular notion. Attitude markers help readers understand the mood in which the author presents the idea through the following sub-categorisation:

\section{a) Subordinate Conjunction}

Words, like although and since, are subordinate conjunctions. These words can be used as indicators of contrastive facts regarding the topic of research or to indicate a relational cause and effect or an outcome regarding a concept. Subordinate conjunctions used by the business and management authors in Pakistani research articles were 'while' (22\%), 'even though' (8\%), 'rather than' $(6 \%)$, 'although' $(14 \%)$, 'whereas' (12\%), 'because' $(8 \%)$ and 'since' $(10 \%)$. The most frequently occurring subordinate conjunction was 'while' with 11 occurrences. Total of $40(80 \%)$ research article introductions projected the use of subordinate conjunctions.

Table 3. Occurrences of subordinate conjunctions in BMS RAs

\begin{tabular}{llll}
\hline Subordinate conjunctions & Number of introductions & $\begin{array}{l}\text { Total number of } \\
\text { occurrences }\end{array}$ & $\begin{array}{l}\text { Percentage (out of 50 } \\
\text { BMS RAs) }\end{array}$ \\
\hline While & INTRO.1, INTRO.6, INTRO.8, INTRO.19, & 11 & $22 \%$ \\
& INTRO.21, INTRO.23, INTRO.26, INTRO.36, & & \\
& INTRO.41, INTRO.44, INTRO.50 & & $8 \%$ \\
Even Though & INTRO.1, INTRO.14, INTRO.28, INTRO.30 & 4 & $6 \%$ \\
Rather than & INTRO.1, INTRO.6, INTRO.39 & 3 & $14 \%$ \\
Although & INTRO.4, INTRO.6, INTRO.17, INTRO.27, & 7 & \\
& INTRO.36, INTRO.37, INTRO.47 & & $12 \%$ \\
Whereas & INTRO.8, INTRO.12, INTRO.17, INTRO.19, & 6 & \\
& INTRO.22, INTRO.35 & & $8 \%$ \\
Because & INTRO.33, INTRO.37, INTRO.44, INTRO.49 & 4 & $10 \%$ \\
Since & INTRO.7, INTRO.31, INTRO.36, INTRO.42, & 5 & \\
\hline
\end{tabular}

b) Conjunctions

Attitude markers can be projected via the use of conjunctions. The two most commonly used conjunctions by the BMS authors were 'but' (58\%) and 'yet' (12\%). 'But' was found in 35 introductions which makes more than half of the articles studied for this research depicting that use of this conjunction highlights contradiction, argument and comparison developed by the author. Therefore, it is evident that the importance of educating our students and young scholars is crucial so that they know how to use language effectively in order to pose authorial stance.

Table 4. Occurrence of conjunctions in BMS RAs

\begin{tabular}{lll}
\hline Conjunctions & Introduction Number & Number of Occurrences \\
\hline But & INTRO.1, INTRO.2, INTRO.3, INTRO.11, INTRO.12, INTRO.13, INTRO.15, & 29 \\
& INTRO.16, INTRO.17, INTRO.22, INTRO.27, INTRO.31, INTRO.32, INTRO.33, \\
& INTRO.34, INTRO.35, INTRO.37, INTRO.39, INTRO.41, INTRO.49 \\
Yet & INTRO.3, INTRO.6, INTRO.7, INTRO.18, INTRO.22, INTRO.28 & 6 \\
\hline
\end{tabular}

c) Nouns

Attitude markers can also be found disguised as nouns which further draws readers' attention to the facts under discussion. 48 out of $50(96 \%)$ authors from business and management sciences made use of nouns as attitude 
markers. Nouns acting like attitude markers included uncertainty, shortcoming, conviction, and more. Please refer to Table 5 for details.

Table 5. Occurrences of nouns depicting attitude markers in BMS RAs

\begin{tabular}{|c|c|}
\hline Number of Introduction & Nouns Acting as Attitude Markers \\
\hline INTRO.1 & Uncertainty, shortcoming, conviction, doubts, conflict, probability \\
\hline INTRO. 2 & Delay, failure, losses, uncertainty, liabilities \\
\hline INTRO. 3 & Perils, problems, uncertainty, transparency, usefulness \\
\hline INTRO.4 & Effectiveness \\
\hline INTRO. 5 & Decline, production \\
\hline INTRO.6 & Improvements, importance, rigidity \\
\hline INTRO.7 & Development, crises, stagnation, decline, turmoil, openness, regard, significance \\
\hline INTRO.8 & Problem, uncertainty, gap \\
\hline INTRO.9 & Innovation \\
\hline INTRO.10 & Rivalry, importance, dilemma, declines, rigidities \\
\hline INTRO.11 & - \\
\hline INTRO.12 & Majority, deficits, imbalances \\
\hline INTRO.13 & Focus, opinion \\
\hline INTRO.14 & Needs \\
\hline INTRO.15 & Acceptance, awareness, problems, understanding, effectiveness, risk \\
\hline INTRO.16 & Harm, gap \\
\hline INTRO.17 & Problems, barrier, assumptions, advantages, distress, abundance \\
\hline INTRO. 18 & Crises, significance \\
\hline INTRO.19 & Helplessness, focus \\
\hline INTRO.20 & Significance, shortcomings \\
\hline INTRO.21 & Nightmares, needs, responsibilities \\
\hline INTRO.22 & Losses \\
\hline INTRO.23 & Importance, losses, limitation, benefit \\
\hline INTRO.24 & Focus, interest, objective \\
\hline INTRO.25 & Satisfaction, barriers \\
\hline INTRO.26 & Importance \\
\hline INTRO.27 & - \\
\hline INTRO.28 & Efficiency, target, gap \\
\hline INTRO.29 & Contribution, success, motivator, frustration, motivation \\
\hline INTRO.30 & Amazement, turning point \\
\hline INTRO.31 & Satisfaction, needs, interaction, focus, challenge, preference \\
\hline INTRO.32 & Strength, weakness, divergence, disagreement, risk, danger \\
\hline INTRO.33 & Barriers, success \\
\hline INTRO.34 & Profit, loss \\
\hline INTRO.35 & Adaptability, creativity, threat, effectiveness, preferences \\
\hline INTRO.36 & Significance, tool, support, importance, value, efficiency, shortcoming \\
\hline INTRO.37 & Importance, needs, instability \\
\hline INTRO.38 & Tool, benefits \\
\hline INTRO.39 & Majorly, obligation, unfairness, inequity, inspiration, importance \\
\hline INTRO.40 & Disagreement, conflicts, liking, disliking, problem, impact \\
\hline INTRO.41 & Root cause, problems, issues \\
\hline INTRO.42 & Attraction, potential, challenge, improvement \\
\hline INTRO.43 & Effectiveness \\
\hline INTRO.44 & Uncertainty \\
\hline INTRO.45 & Need, driver, alternative \\
\hline INTRO.46 & Importance, barriers, exception, burden \\
\hline INTRO.47 & $\begin{array}{l}\text { Priority, turnover, satisfaction, violation, sabotage, disorder, frustration, depression, lethargy, } \\
\text { insomnia, effectiveness, problems, betterment, needs, moral values, laxity }\end{array}$ \\
\hline INTRO.48 & Focus, benchmark, interest \\
\hline INTRO.49 & Significance, exploitation, problems, attention, contribution \\
\hline INTRO.50 & Importance, advantage, satisfaction, effectiveness, barrier, hindrance \\
\hline
\end{tabular}




\section{d) Negatives}

Negative attitude of authors can also be studied via the use of negative words. In the study conducted for this article, it was found that 42 out of $50(84 \%)$ introduction sections of the sample research articles had the use of negatives. The most commonly used negative was 'not' which occurred 40 times in 27 articles. Other negatives used were neither, did not, have not, cannot, no, do not, doesn't, never, has not and may not. Hence, it was concluded that effective usage of indicators of negatives helped authors show denial and negation regarding the topic under discussion. Such language was also used in order to refer to disagree with another author of the research under the same topic.

Table 6. Occurrences of negatives indicating attitude markers in BMS RAs

\begin{tabular}{|c|c|c|}
\hline Negatives Indicating Attitude Markers & Number of Introduction & Total Number of Occurrences \\
\hline Not & $\begin{array}{l}\text { INTRO.1, INTRO.3, INTRO.4, INTRO.6, } \\
\text { INTRO.11, INTRO.12, INTRO.13, INTRO.15, } \\
\text { INTRO.16, INTRO.17, INTRO.18, INTRO.21, } \\
\text { INTRO.22, INTRO.24, INTRO.26, INTRO.28, } \\
\text { INTRO.31, INTRO.32, INTRO.33, INTRO.34, } \\
\text { INTRO.41, INTRO.44, INTRO.45, INTRO.46, } \\
\text { INTRO.47, INTRO.48, INTRO.49 }\end{array}$ & 40 \\
\hline Neither & INTRO.1, INTRO.14, INTRO.24 & 4 \\
\hline Did not & INTRO.1, INTRO.2, INTRO.30 & 4 \\
\hline Have not & INTRO.1, INTRO.9, INTRO.37 & 3 \\
\hline Cannot & INTRO.1, INTRO.6, INTRO.7 & 3 \\
\hline No & $\begin{array}{l}\text { INTRO.2, INTRO.6, INTRO.17, INTRO.22, } \\
\text { INTRO.32, INTRO.37, INTRO.40, INTRO. } 43 \text {, } \\
\text { INTRO.47, INTRO.48, INTRO.50 }\end{array}$ & 16 \\
\hline Do not & $\begin{array}{l}\text { INTRO. } 4, \text { INTRO. } 6 \text {, INTRO. } 8, \text { INTRO. } 21, \\
\text { INTRO. } 45, \text { INTRO. } 47, \text { INTRO. } 48\end{array}$ & \\
\hline Does not & INTRO.10, INTRO.26 & 2 \\
\hline Never & INTRO.20, INTRO.30 & 2 \\
\hline Has not & INTRO.22, INTRO.26, INTRO.46 & 3 \\
\hline May not & INTRO.39 & 1 \\
\hline
\end{tabular}

e) Comparatives and Superlatives

Employment of comparatives and superlatives by the BMS authors in their RAs showed that they preferred using these degrees of adjectives besides the use of adjectives and adverbs to express the intensity and seriousness or thereof, lack of seriousness in relation to the topics under discussion. $66 \%$ of comparatives and $62 \%$ of superlatives were effectively used by authors. The most frequently used and recurring comparative and superlative were 'more' and 'most'. Use of comparatives and superlatives significantly induced the degree of importance a phenomenon was being given under topic of study. It was only in $8 \%$ of the RAs where a comparative or superlative was not used. The other $92 \%$ did show the importance of usage in the context of authorial stance. 
Table 7. Occurrences of comparatives indicating attitude markers in BMS RAs

\begin{tabular}{|c|c|c|}
\hline Number of Introduction & Comparatives & Superlatives \\
\hline INTRO.1 & Greater & Highest \\
\hline INTRO. 2 & - & - \\
\hline INTRO. 3 & More & Highest \\
\hline INTRO.4 & Greater, higher, more & Most \\
\hline INTRO. 5 & - & - \\
\hline INTRO.6 & More, better & Most \\
\hline INTRO.7 & Worse & Most \\
\hline INTRO.8 & Higher, riskier & Most \\
\hline INTRO.9 & More, higher & - \\
\hline INTRO.10 & Faster, more & Most \\
\hline INTRO.11 & - & Fastest, highest \\
\hline INTRO.12 & Greater, more & Most \\
\hline INTRO.13 & - & Most \\
\hline INTRO.14 & - & Most, best \\
\hline INTRO.15 & Greater & - \\
\hline INTRO.16 & More, better & Most \\
\hline INTRO.17 & - & Best, most \\
\hline INTRO.18 & - & Most \\
\hline INTRO.19 & - & - \\
\hline INTRO.20 & - & - \\
\hline INTRO.21 & Higher, greater & - \\
\hline INTRO.22 & Lower, better, longer & Most, best \\
\hline INTRO.23 & - & Most \\
\hline INTRO.24 & Higher, more, shorter, lower, higher & Largest \\
\hline INTRO.25 & Earlier & - \\
\hline INTRO.26 & Smaller, greater & - \\
\hline INTRO.27 & More, better & Most \\
\hline INTRO.28 & - & - \\
\hline INTRO.29 & More & - \\
\hline INTRO.30 & Better, easier & - \\
\hline INTRO.31 & More & - \\
\hline INTRO.32 & More & - \\
\hline INTRO.33 & Lower, better & - \\
\hline INTRO.34 & Better & - \\
\hline INTRO.35 & More, wider, better & Fullest, best \\
\hline INTRO.36 & Higher, more, better & Most \\
\hline INTRO.37 & - & Best, most \\
\hline INTRO.38 & - & - \\
\hline INTRO.39 & - & - \\
\hline INTRO.40 & More & Most \\
\hline INTRO.41 & More, better & Most, best \\
\hline INTRO.42 & More & Most \\
\hline INTRO.43 & More & Most \\
\hline INTRO.44 & Higher & Best \\
\hline INTRO.45 & - & Largest \\
\hline INTRO.46 & - & - \\
\hline INTRO.47 & Greater, more & Best \\
\hline INTRO.48 & - & Oldest \\
\hline INTRO.49 & More, greater, larger & Least \\
\hline INTRO.50 & Higher, lower, bigger & Most \\
\hline Total occurrences & 33 & 31 \\
\hline Percentages & $66 \%$ & $62 \%$ \\
\hline
\end{tabular}

\section{f) Attitude Verbs}

This variety of verbs shows authorial attitude. $100 \%$ of the RAs showed usage of attitude verbs. Their classification, however, depicted negative and positive attitudes, depending upon the context. Negative attitude verbs included contradict, discredited, suffered, refused, and more. Please refer to Table 8 below for a detailed 
list of attitude verbs as used by the authors from the BMS discourse community. The variety of attitude verbs used by the BMS authors depicts how they emphasised the actions via the use of positive and negative attitude verbs in order to show emotion and sentiments associated with words they produce.

Table 8. Occurrence of verbs indicating attitude markers in BMS RAs

\begin{tabular}{|c|c|}
\hline Number of Introduction & Verbs Indicating Attitude Markers \\
\hline INTRO.1 & Preferred, strengthened, emphasize, contradict, highlighted, discredited \\
\hline INTRO.2 & Suffered, refused, expect \\
\hline INTRO.3 & Facilitates \\
\hline INTRO. 4 & Maximize, reduce \\
\hline INTRO.5 & Attributed, confirmed \\
\hline INTRO.6 & Argue, emphasize, adjust, allow, assumed, differ \\
\hline INTRO.7 & Increased, facilitated, promote, triggered, encouraged, referred, underestimated, investigated, perfected \\
\hline INTRO.8 & Considered \\
\hline INTRO.9 & Argued, predicting, consider \\
\hline INTRO.10 & Helps, attempts \\
\hline INTRO.11 & Targeting, promoted, ensure \\
\hline INTRO.12 & Manipulated, focused, affecting, persuade \\
\hline INTRO.13 & Focuses, recommended, required \\
\hline INTRO.14 & Refers, ensures, fits, affecting, contribute \\
\hline INTRO.15 & Entangling, befitting, think, feel, realize, enhancing, help, aid \\
\hline INTRO.16 & Exceeds, preferred, contribute, distorts, targeting, attempts, help \\
\hline INTRO.17 & Prefer, modified, seek to, predict \\
\hline INTRO.18 & Affect, considered, reviews, ratifies, contributes, concerns, consider, facilitates \\
\hline INTRO.19 & Consider, attempt, contribute, influencing \\
\hline INTRO.20 & Refers, depend, add, contributes \\
\hline INTRO.21 & Maximize, follow, prohibits, promote, boosts \\
\hline INTRO.22 & Contributes, presents, offers, allows \\
\hline INTRO.23 & Fulfill, cancelled, improve \\
\hline INTRO.24 & Suggest, presumes, believe, opposed, offer, signifies, fail \\
\hline INTRO.25 & Pursued \\
\hline INTRO.26 & Considered, believe, supports, aims, concludes, rejects \\
\hline INTRO.27 & Prefer, highlight, demands, lack, contribute, recognized \\
\hline INTRO.28 & Increase, improve, considering, boosts, consider \\
\hline INTRO.29 & Ensure \\
\hline INTRO.30 & Agree, deviate \\
\hline INTRO.31 & Cater, believed, needs to, capture, noted, estimated \\
\hline INTRO.32 & Clarified, ponder, support \\
\hline INTRO.33 & Encouraged, enables, reduced, avail, attracting, enduring, enhance \\
\hline INTRO.34 & Preferred, enhance \\
\hline INTRO.35 & Pursue, lack, preferred, requires, insists, regarded, contribute, facilitate \\
\hline INTRO.36 & Refers, expressed, boost, focused, survive, compete, declared, awarded, proved, reveals \\
\hline INTRO.37 & Affects, identified, recovered, focused, jolted \\
\hline INTRO.38 & - \\
\hline INTRO.39 & Encourage, familiarized, illustrated, enhance, emphasized, contributed, examine, recognize \\
\hline INTRO.40 & Affecting, facilitates, enhance, understand, clarify \\
\hline INTRO.41 & Determine, adopted, focus, strength, contribute, ensure, reflects \\
\hline INTRO.42 & Agreed, ensure, attract, targeting \\
\hline INTRO.43 & Accepted, focusing, need to, suggested, proves, supported, perceived, highlight \\
\hline INTRO.44 & Honoring, fail, rejected, affects, demand, affect, focused \\
\hline INTRO.45 & Contribute, tested, affect \\
\hline INTRO.46 & Diminishing, to seek, affects, concludes \\
\hline INTRO.47 & Encourage, fails, proves, guarantee, perceive \\
\hline INTRO.48 & Exhibits, consists, reflect, improving, attract \\
\hline INTRO.49 & Emphasized, focused, controls, interacts, protect, benefits \\
\hline INTRO.50 & Emphasized, refers, distinguished, prefer, request, contributing, revealed \\
\hline
\end{tabular}

\section{g) Adverbs}

According to Adams and Quintana-Toledo (2013), adverbs are magic words which can communicate doubt and certainty, actuality and reality, the source of knowledge, limitation, viewpoint and perspective and imprecision. It was found that such attitude markers using adverbs were observed in $100 \%$ RAs. These words not only convey the approach of the author but also exhibit the opinions related to them. It was observed that the most frequently occurring adverbs depicting attitude were 'therefore' (69\%) and 'however' $(54 \%)$. Such adverbs showing 
author's attitude projected different meanings at different points. Table 9 shows the details of adverbs indicating attitude found in the BMS RAs. Thisevidently suggested that genre-based pedagogy needs to be incorporated with such language conventions where research scholars know the type of language they should or should not use for the production of an RA in their fields and sub-fields of study.

Table 9. Occurrences of adverbs indicating attitude markers in BMS RAs

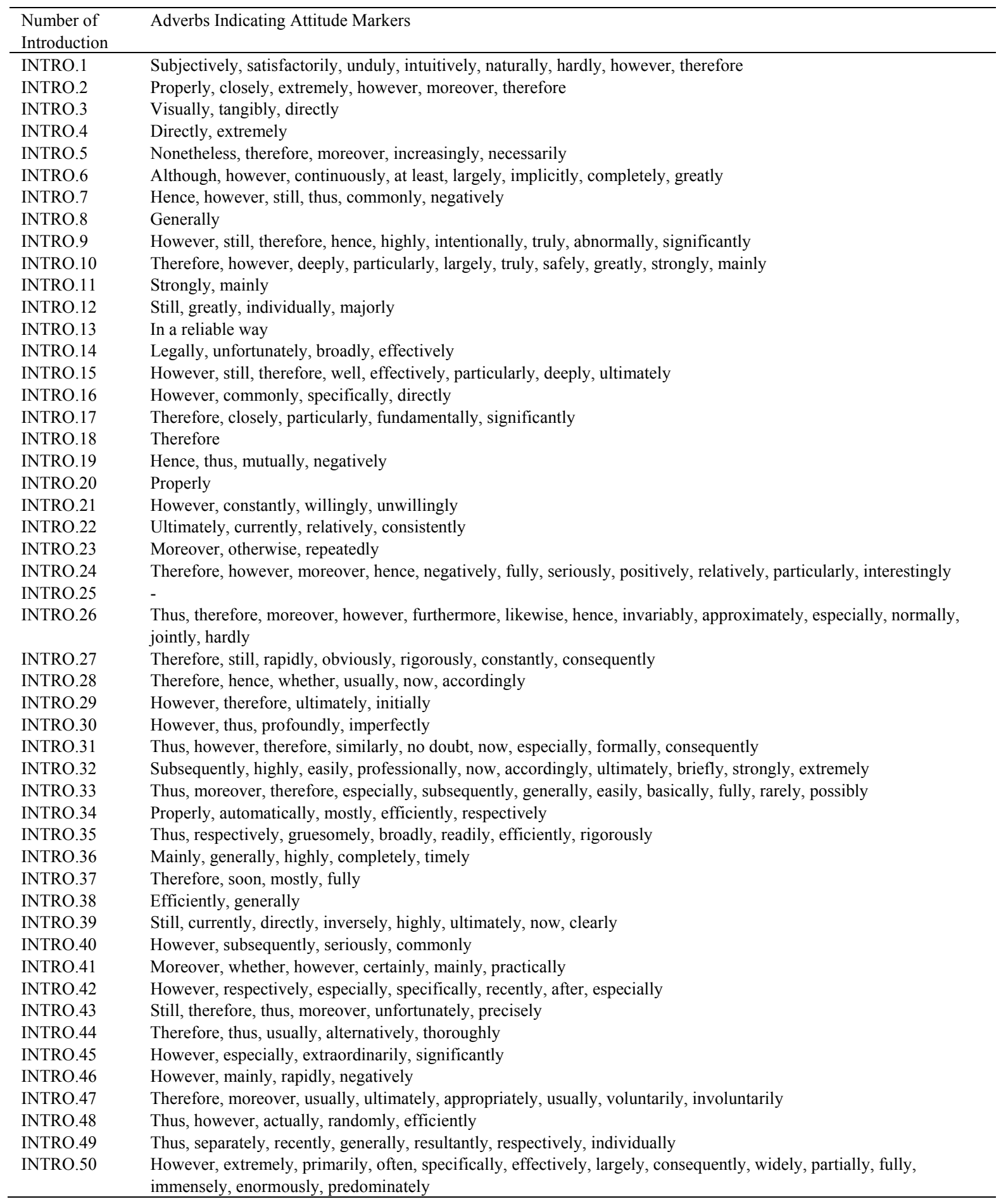




\section{h) Adjectives}

It was noticed that adjectives were also used by the authors of BMS RAs to project attitude. Through the usage of adjectives, these authors inculcated their opinions, views and judgements by taking help from suitable adjectives regarding the area of research. $100 \%$ of the BMS RAs had a significant usage of indicators of attitude via adjectives. A total of 160 different adjectives projecting authorial attitude were found in BMS RAs which showed that correct use of language within the boundaries of the discourse community couldactually create a strong impact on readers.

Table 10. Occurrences of adjectives indicating attitude markers in BMS RAs

\begin{tabular}{|c|c|}
\hline $\begin{array}{l}\text { Number of } \\
\text { Introduction }\end{array}$ & Adjectives Indicating Attitude Markers \\
\hline INTRO.1 & $\begin{array}{l}\text { Uncertain, persuasive, diminishing, expected, possible, convincing, increasing, underlying, strict, big, } \\
\text { distinct, paradoxical, debatable }\end{array}$ \\
\hline INTRO.2 & $\begin{array}{l}\text { Fundamental, prominent, major, difficult, advanced, complete, excellent, ideal, bad, improper, damaging, } \\
\text { unwanted, probable, negative, major, unexpected }\end{array}$ \\
\hline INTRO.3 & Useful, very common, important \\
\hline INTRO.4 & Innovative, interactive, popular, effective, desirable, active, limited \\
\hline INTRO.5 & Smart, steep, increasing, sharp, high, unwilling, negative \\
\hline INTRO.6 & $\begin{array}{l}\text { Significant, simple, critical, lagged, important, good, unbalanced, real, sensible, discerning, backward, } \\
\text { perfect, reasonable, well-known, strong, persuasive, maximum }\end{array}$ \\
\hline INTRO.7 & $\begin{array}{l}\text { Accelerated, different, rapid, possible, immediate, new, top, heated, important, integral, increasing, } \\
\text { impossible, clear, effective, high, few }\end{array}$ \\
\hline INTRO.8 & Extensive, influential, pervasive, significant, high, prominent, unable, influential \\
\hline INTRO.9 & Intended, interesting, well-researched \\
\hline INTRO.10 & $\begin{array}{l}\text { Underdeveloped, sustainable, complementary, perfect, soaring, important, less developed, concrete, } \\
\text { necessary, supporting, evident, distressing, fruitless, high, significant, encouraging }\end{array}$ \\
\hline INTRO.11 & Dynamic, robust, stable, sustainable, mature, diversified, rapid, remarkable, successful, crucial, affordable \\
\hline INTRO.12 & $\begin{array}{l}\text { Competitive, rapid, smell, large, negative, bad, continuous, high, new, essential, major, worsening, } \\
\text { discouraging, average, low, primary }\end{array}$ \\
\hline INTRO.13 & Main, special, important, unexpected, possible, purposive, suitable, large \\
\hline INTRO.14 & Useful, defensible, wide, fundamental, current, new, untenable, observable, important, effective \\
\hline INTRO.15 & Wide, popular, special, correct, important, implicit, lack, current, desirable, suitable, positive, minimum \\
\hline INTRO.16 & Low, stable, necessary, self-explanatory, long, important, suitable, recent, increasing, apt \\
\hline INTRO.17 & $\begin{array}{l}\text { Major, concerned, important, vital, current, expected, common, preferred, very difficult, key, different, very } \\
\text { first, perfect, constant }\end{array}$ \\
\hline INTRO.18 & $\begin{array}{l}\text { Responsible, protected, little, positive, negative, key, primary, dominant, efficient, sustainable, new, few, } \\
\text { broad, necessary, appropriate, impartial, proper, indispensible, helpful, effective }\end{array}$ \\
\hline INTRO.19 & Major, different, former, concerned, relative, important, low, \\
\hline INTRO.20 & High, wide, self-regulated, negative, intrinsic, positive, deep, motivational \\
\hline INTRO.21 & $\begin{array}{l}\text { Inevitable, inborn, major, distinguished, entire, underdeveloped, specific, limited, certain, too little, } \\
\text { necessary, essential, possible, efficient, effective }\end{array}$ \\
\hline INTRO.22 & $\begin{array}{l}\text { Main, strong, significant, important, effective, productive, available, least, maximum, clear, small, regulatory, } \\
\text { very impressive, too tiny, small, huge, very low, useful, beneficial, helpful, weak }\end{array}$ \\
\hline INTRO.23 & Vital, unprecedented, remarkable, unexpected, unabsorbed, weak, strong, few, helpful \\
\hline INTRO.24 & $\begin{array}{l}\text { Unpredictable, negative, efficient, predictable, short, long, increased, willing, positive, far, positive, } \\
\text { influential, negative, unstable, peculiar, limited }\end{array}$ \\
\hline INTRO.25 & Recent, various, pioneering, direct, important, new, high, essential, dramatic \\
\hline INTRO.26 & $\begin{array}{l}\text { Vigilant, important, majority, plausible, private, key, interested, accurate, short, long, crucial, available, very } \\
\text { interesting, valid, consistent, doubtful, unable, uninformative, weak }\end{array}$ \\
\hline INTRO.27 & $\begin{array}{l}\text { High, well qualified, dynamic, very valuable, fresh, useful, valuable, proper, ultimate, helpful, important, hot, } \\
\text { inconsistent, appropriate, ideal, neglected, positive, popular, prominent, recent }\end{array}$ \\
\hline INTRO.28 & Competitive, immense, essential, current, effective, inefficient \\
\hline INTRO.29 & Important, familiar, obvious, sentimental, concerned \\
\hline INTRO.30 & Prominent, noticeable, profound, inquired, rejected \\
\hline INTRO.31 & $\begin{array}{l}\text { Psychological, latest, new, difficult, intangible, high, competitive, serious, maximum, positive, well aware, } \\
\text { imperative, chief }\end{array}$ \\
\hline INTRO.32 & $\begin{array}{l}\text { Successful, good, positive, beneficial, qualitative, senior, great, very valid, very different, extra clear, } \\
\text { accurate, realistic, unexpected, negative, proper }\end{array}$ \\
\hline INTRO.33 & Successful, important, potent, primary \\
\hline INTRO.34 & Efficient, unnecessary, vital, declining, \\
\hline INTRO.35 & Basic, common, adequate, successful, productive, beneficial, concrete, reckless, particular, rich, significant \\
\hline INTRO.36 & Peak, important, high, new, prestigious, full, small, top class \\
\hline INTRO.37 & $\begin{array}{l}\text { Outstanding, efficient, right, safe, previous, sensitive, natural, safe, negative, limited, few, mixed, } \\
\text { inconclusive, a little bit, numerous, intense, terrifying, huge, big }\end{array}$ \\
\hline
\end{tabular}




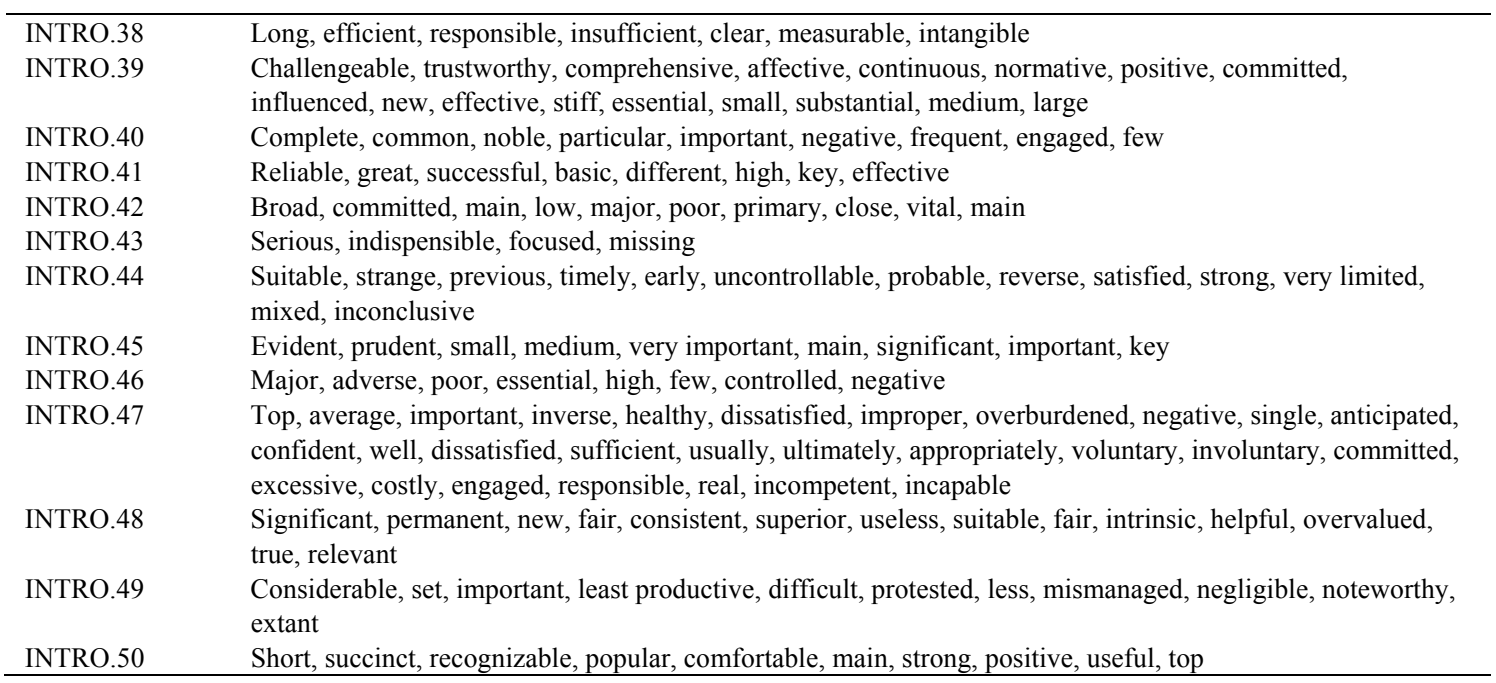

It can be concluded after the in-depth study of BMS RAs that the authors of business and management sciences RAs inculcated attitude markers as the requirement for their production of RAs to make sure that their opinions, perceptions and ideas were correctly perceived. It was evident that due to the need for bringing details together and make the whole process of production elucidated and well-explained, it was necessary for them to use attitude markers as a crucial feature.

\section{4) Self-Mention}

Authors of BMS RAs did not use personal pronouns and possessive adjectives to determine the presence of self and to highlight the interpersonal communicative skills (which engaged them more with their readers) as much they did other features of stance. It is an important feature of stance which is strongly recommended to be used during the presentation of one's ideas as an author (Hyland, 2001). Ivanic (1998) suggested that presenting self is one of the most efficient and significant ideas in any piece of writing. In the present study, it was observed that writers of BMS RAs did not make much use of self-mention. They used the pronoun 'we' which stated that they associate a sense of generalisation to the mentioned fact or piece of information. It can be rightly said that such usage of self-mention gives authors a sense of surety that their readers will also come to the same conclusion as themselves. At sometimes, it was observed that 'we' referred to the co-authors/co-researchers. Other times, it was used to get into a team with the readers. In totality, it was used in only 9 out of $50(18 \%)$ RAs. The use of the personal pronoun 'I' was used in only 1 out of $50(2 \%)$ articles which concluded that authors chose to remain objective rather than being subjective about the notion under discussion. 'Our' was used in 2 out of 50 (4\%) while 'ours' was used in 1 out of 50 (2\%) RAs. This information suggested that the use of self-mention may not be given much attention in the said field. The reason which this study drew from this fact was that objectivity rather than subjectivity was a preferred authors' choice in the field BMS.

Table 11. Occurrences of self-mention in BMS RAs

\begin{tabular}{lll}
\hline Indicators of Self Mention & Number of Introduction & Number of Occurrences \\
\hline We & INTRO.3, INTRO.6, INTRO.7, INTRO.8, & 11 \\
& INTRO.10, INTRO.13, INTRO.16, INTRO.19, & \\
& INTRO.43 & 2 \\
Our & INTRO.7, INTRO.13 & 1 \\
Ours & INTRO.6 & 1 \\
I & INTRO.40 & \\
\hline
\end{tabular}

\section{Discussion}

After analysing 50 BMS RAs, it was observed that most of the authors in the field of business and management sciences used the features of stance, other than self-mention, like a compulsion. The discussion above shows the utility of stance features by BMS RA authors at great lengths. The most used features of stance were concluded to be the attitude marker(s) which shows the certain need of inculcation of appropriately lexical items to show BMS researchers' attitudes, dimensions of thought and opinions. It was observed that careful use of stance 
features was made as authors wished to keep the degree of agreement and/or disagreement within safe boundaries of their discourse community regarding connecting with their readers via authorial stance. The same phenomenon can be observed in Table 12 which shows the presence of Stance Features in all 50 samples of BMS RAs at a glance.

Table 12. Occurrences of features of stance in BMS RAs

\begin{tabular}{|c|c|c|c|c|}
\hline Number of Introduction & Hedges & Boosters & Attitude Markers & Self-Mention \\
\hline INTRO.1 & $\sqrt{ }$ & $\sqrt{ }$ & $\sqrt{ }$ & $x$ \\
\hline INTRO.2 & $\sqrt{ }$ & $\sqrt{ }$ & $\sqrt{ }$ & $x$ \\
\hline INTRO.3 & $\sqrt{ }$ & $\sqrt{ }$ & $\sqrt{ }$ & $\sqrt{ }$ \\
\hline INTRO.4 & $\sqrt{ }$ & $\sqrt{ }$ & $\sqrt{ }$ & $x$ \\
\hline INTRO.5 & $x$ & $\sqrt{ }$ & $\sqrt{ }$ & $x$ \\
\hline INTRO.6 & $\sqrt{ }$ & $\sqrt{ }$ & $\sqrt{ }$ & $\sqrt{ }$ \\
\hline INTRO.7 & $\sqrt{ }$ & $\sqrt{ }$ & $\sqrt{ }$ & $\sqrt{ }$ \\
\hline INTRO.8 & $\sqrt{ }$ & $\sqrt{ }$ & $\sqrt{ }$ & $\sqrt{ }$ \\
\hline INTRO.9 & $x$ & $\sqrt{ }$ & $\sqrt{ }$ & $x$ \\
\hline INTRO.10 & $x$ & $\sqrt{ }$ & $\sqrt{ }$ & $\sqrt{ }$ \\
\hline INTRO.11 & $x$ & $\sqrt{ }$ & $\sqrt{ }$ & $x$ \\
\hline INTRO.12 & $x$ & $\sqrt{ }$ & $\sqrt{ }$ & $x$ \\
\hline INTRO.13 & $x$ & $x$ & $\sqrt{ }$ & $\sqrt{ }$ \\
\hline INTRO.14 & $\sqrt{ }$ & $x$ & $\sqrt{ }$ & $x$ \\
\hline INTRO.15 & $\sqrt{ }$ & $\sqrt{ }$ & $\sqrt{ }$ & $x$ \\
\hline INTRO.16 & $\sqrt{ }$ & $\sqrt{ }$ & $\sqrt{ }$ & $\sqrt{ }$ \\
\hline INTRO.17 & $\sqrt{ }$ & $\sqrt{ }$ & $\sqrt{ }$ & $x$ \\
\hline INTRO. 18 & $x$ & $x$ & $\sqrt{ }$ & $x$ \\
\hline INTRO.19 & $\sqrt{ }$ & $\sqrt{ }$ & $\sqrt{ }$ & $\sqrt{ }$ \\
\hline INTRO. 20 & $\sqrt{ }$ & $x$ & $\sqrt{ }$ & $x$ \\
\hline INTRO.21 & $\sqrt{ }$ & $x$ & $\sqrt{ }$ & $x$ \\
\hline INTRO.22 & $\sqrt{ }$ & $\sqrt{ }$ & $\sqrt{ }$ & $x$ \\
\hline INTRO.23 & $\sqrt{ }$ & $x$ & $\sqrt{ }$ & $x$ \\
\hline INTRO. 24 & $\sqrt{ }$ & $x$ & $\sqrt{ }$ & $x$ \\
\hline INTRO.25 & $\sqrt{ }$ & $\sqrt{ }$ & $\sqrt{ }$ & $x$ \\
\hline INTRO.26 & $x$ & $x$ & $\sqrt{ }$ & $x$ \\
\hline INTRO.27 & $\sqrt{ }$ & $\sqrt{ }$ & $\sqrt{ }$ & $x$ \\
\hline INTRO.28 & $\sqrt{ }$ & $x$ & $\sqrt{ }$ & $x$ \\
\hline INTRO.29 & $\sqrt{ }$ & $\sqrt{ }$ & $\sqrt{ }$ & $x$ \\
\hline INTRO.30 & $x$ & $\sqrt{ }$ & $\sqrt{ }$ & $x$ \\
\hline INTRO.31 & $\sqrt{ }$ & $\sqrt{ }$ & $\sqrt{ }$ & $x$ \\
\hline INTRO.32 & $\sqrt{ }$ & $\sqrt{ }$ & $\sqrt{ }$ & $x$ \\
\hline INTRO.33 & $\sqrt{ }$ & $\sqrt{ }$ & $\sqrt{ }$ & $x$ \\
\hline INTRO.34 & $\sqrt{ }$ & $\sqrt{ }$ & $\sqrt{ }$ & $x$ \\
\hline INTRO.35 & $\sqrt{ }$ & $x$ & $\sqrt{ }$ & $x$ \\
\hline INTRO.36 & $\sqrt{ }$ & $\sqrt{ }$ & $\sqrt{ }$ & $x$ \\
\hline INTRO.37 & $\sqrt{ }$ & $\sqrt{ }$ & $\sqrt{ }$ & $x$ \\
\hline INTRO.38 & $x$ & $x$ & $\sqrt{ }$ & $x$ \\
\hline INTRO.39 & $\sqrt{ }$ & $\sqrt{ }$ & $\sqrt{ }$ & $x$ \\
\hline INTRO.40 & $x$ & $x$ & $\sqrt{ }$ & $x$ \\
\hline INTRO.41 & $\sqrt{ }$ & $\sqrt{ }$ & $\sqrt{ }$ & $x$ \\
\hline INTRO.42 & $\sqrt{ }$ & $\sqrt{ }$ & $\sqrt{ }$ & $x$ \\
\hline INTRO.43 & $x$ & $\sqrt{ }$ & $\sqrt{ }$ & $\sqrt{ }$ \\
\hline INTRO.44 & $\sqrt{ }$ & $x$ & $\sqrt{ }$ & $x$ \\
\hline INTRO.45 & $x$ & $x$ & $\sqrt{ }$ & $x$ \\
\hline INTRO.46 & $\sqrt{ }$ & $x$ & $\sqrt{ }$ & $x$ \\
\hline INTRO.47 & $\sqrt{ }$ & $\sqrt{ }$ & $\sqrt{ }$ & $x$ \\
\hline INTRO.48 & $\sqrt{ }$ & $\sqrt{ }$ & $\sqrt{ }$ & $x$ \\
\hline INTRO.49 & $\sqrt{ }$ & $\sqrt{ }$ & $\sqrt{ }$ & $x$ \\
\hline INTRO.50 & $x$ & $\sqrt{ }$ & $\sqrt{ }$ & $x$ \\
\hline Total Occurrences & 36 & 35 & 50 & 9 \\
\hline Percentage & $72 \%$ & $70 \%$ & $100 \%$ & $18 \%$ \\
\hline
\end{tabular}


As Table 12, above, suggests how lavishly the authors of RAs in the field of BMS in Pakistan use the stance features, it is clear that the need to bring a change in genre-pedagogy is need of the day. To stress on the same, Figure 2 depicts the leverage these authors take when it comes to the use of stance markers.

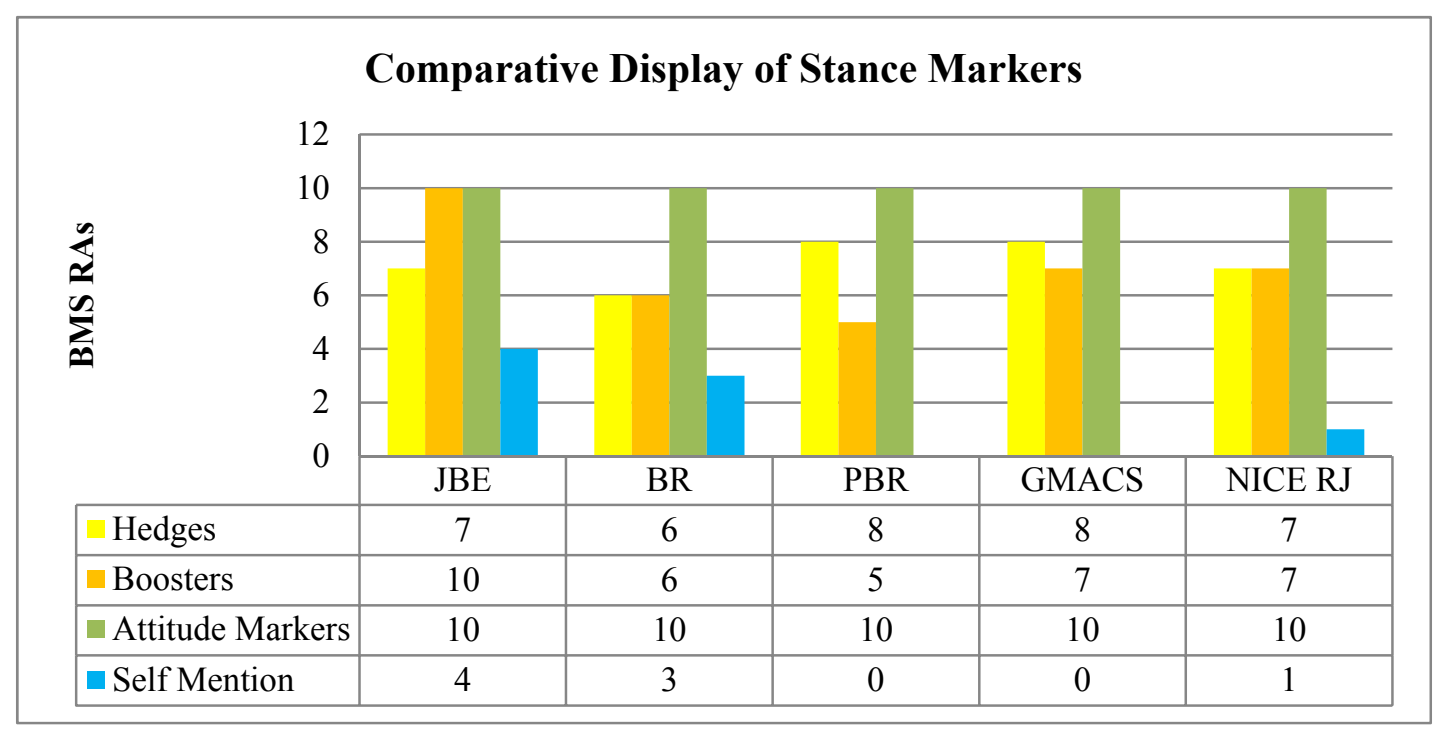

Figure 2. Occurrences of features of stance in BMS research journals

After the comparative analysis of all the BMS RAs it is observed that features of stance are being utilized by most of the BMS researchers. The features of Attitude Markers are found in all the BMS RAs that shows an unavoidable need of the inculcation of words that depict BMS researchers' attitudes, opinions and dimensions of thought. Hedges and Boosters are also being employed by the BMS Researchers in the most of the BMS RAs. The feature of Self Mention is found the least that depicts BMS researchers' emphasis objective presentation rather than the subjective one.

In the light of findings of the present study, I would like to make a few recommendations to the Higher Education Commission (HEC), Pakistan, university teachers, students and future researchers. This study can be advantageous in many ways as suggested below:

1) HEC, Pakistan can use the study as a basis for investing in genre-awareness and genre-based pedagogy as we as a nation clearly lag behind in this area of educational research. If proper funds are granted to genre-analysts and researcher, more of such studies can be conducted at a larger scale with more data and more in-depth study.

2) The present findings can be of great help if university teachers expand their understanding of genre-awareness and help their BMS students with genre-competence.

3) Students from the field of BMS striving to learn how to write a generically-competent RA in their field can benefit from this study and explore the area more by reading more as directed in references.

4) For future researchers, it is important to look into the same genre with more depth and conduct research works of the same nature for other disciplines in Pakistan. They are also recommended to study other academic genres in order to make contributions to the Pakistani and international research community.

\section{References}

Akbarpour, M., \& Sadeghoghli, H. (2015). The Study on Ken Hyland's Interactional Model in OUP Publications. International Journal of Language and Linguistics, 3(4), 266-270. https://doi.org/10.11648/j.ijl1.20150304.21

Allami \& Serajfard. (2012). Engagement Markers: a Technique for Improving Writing Skills. Journal of Language, Culture, and Translation (LCT), 1(1), 71-83

Barbero, M. (2008). Business History in Latin America: A Historiographical Perspective. Business History Review, 82(3). https://doi.org/10.1017/S0007680500082647 
Bellah, R. (1967). Civil Religion in America. In Daedalus: Journal of the American Academy of Arts and Sciences. Cambridge: MIT Press.

Chandler, A. D. (1962). Strategy and Structure: Chapters in the History of the Industrial Enterprise. Cambridge: MIT Press.

Fligstein, N. (2008). Euroclash: The EU, European Identity, and the Future of Europe. Oxford, U.K.: Oxford University Press.

Friedman, M. M., Bowden, V. R., \& Jones, E. G. (2003). Family Nursing: Research, Theory, \& Practice (5th ed.). New Jersey: Pearson Education Inc.

Hyland, K. (1999). Talking to students: Metadiscourse in introductory textbooks. English for Specific Purposes, 18(1), 3-26. https://doi.org/10.1016/S0889-4906(97)00025-2

Hyland, K. (2000). Disciplinary Discourses: Social Interactions in Academic Writing. Harlow, Essex: Longman.

Hyland, K. (2001). Bringing in the Reader: Addressee Features in Academic Writing. Written Communication, 18(4), 549-574. https://doi.org/10.1177/0741088301018004005

Hyland, K. (2002a). Authority and Invisibility: authorial identity in academic writing. Journal of Pragmatics, 34, 1091-1112. https://doi.org/10.1016/S0378-2166(02)00035-8

Hyland, K. (2002b). Directives: Power and Engagement in Academic Writing. Applied Linguistics, 23(2), $215-$ 239. https://doi.org/10.1093/applin/23.2.215

Hyland, K. (2005a). Stance and engagement: a model of interaction in academic discourse. Discourse Studies, 7(2), 173-192. https://doi.org/10.1177/1461445605050365

Hyland, K. (2005b). Stance and Engagement: A model of interaction in academic discourse. Retrieved from http://dis.sagepub.com/cgi/content/abstract/7/7/173

Hyland, K. (2006). English for Academic Purposes: An advanced resource book. Routledge, London.

Navidi \& Ghafoori. (2015). DU Journal: Functions of Interaction in Applied Linguistics. Humanities and Social Sciences, 8(1), 634-647.

Sayah, L., \& Hashemi, M. R. (2014). Exploring stance and engagement features in discourse analysis papers. Theory and Practice in Language Studies, 4(3).

Swales, J. M. (1984). Research into the structure of introductions to journal articles and its application to the teaching of academic writing. In R. Williams, J. Swales \& J. Kirkman (Eds.), Common Ground: Shared Interests in ESP and Communication Studies (pp. 77-86). Oxford: Pergamon.

Swales, J. M. (1990). Genre Analysis: English in Academic and Research Settings (p. 374). Cambridge: Cambridge University

Toms, S., Wilson, N., \& Wright, M. (2015). The Evolution of Private Equity: Corporate Restructuring in the UK. Business History, 57(5), 736-768. https://doi.org/10.1080/00076791.2014.977262

Wittgenstein, L. (1958). Philosophical Investigations (pp. 32-33). Oxford: Basil Blackwell.

Wittgenstein, L. (1980). Remarks on the Philosophy of Psychology, I \& II. Oxford: Basil Blackwell.

\section{Notes}

Abbreviations:RA for a research article, BMS for Business and Management Sciences, HEC for Higher Education Commission. JBE for Journal of Business and Economics, BR for Business Review, PBR for Pakistan Business Review, GMACS for Global Management Journal for Academic \& Corporate Studies, NICE for Newport Institute of Communications and Economic Research.

\section{Copyrights}

Copyright for this article is retained by the author, with first publication rights granted to the journal.

This is an open-access article distributed under the terms and conditions of the Creative Commons Attribution license (http://creativecommons.org/licenses/by/4.0/). 